\title{
Evaluation of Tryptophan/Kynurenine Pathway Relevance With Immune System Biomarkers of Low Energy Trauma Hip Fractures in Osteoporotic Patients
}

\author{
Ercan DİNÇEL, ${ }^{1}$ Yeşim ÖZKAN, ${ }^{2}$ Murat ŞÜKÜROĞLU, ${ }^{3}$ \\ Hakan ÖZSOY, ${ }^{1}$ Aylin SEPİCİ DİNÇEL ${ }^{4}$ \\ ${ }^{1}$ Department of Orthopedics and Traumatology, University of Health Sciences, Ankara Training and Research Hospital, Ankara, Turkey \\ ${ }^{2}$ Department of Biochemistry, University of Gazi, Faculty of Pharmacy, Ankara, Turkey \\ ${ }^{3}$ Department of Pharmaceutical Chemistry, University of Gazi, Faculty of Pharmacy, Ankara, Turkey \\ ${ }^{4}$ Department of Medical Biochemistry, University of Gazi, Faculty of Medicine, Ankara, Turkey
}

\begin{abstract}
Objectives: This study aims to evaluate tryptophan degradation and clarify whether altered levels of kynurenine and tryptophan (Kyn/Trp) ratio could be correlated to osteoporotic hip fractures via immune system.

Patients and methods: The study included 60 patients with osteoporotic hip fracture $(20$ males, 40 females, mean age $76.6 \pm 6.9$ years; range 59 to 95 years). Patients were divided into two as patients with collum femoris fractures (group $1 ; n=23$ ) and intertrochanteric fractures (group 2; $\mathrm{n}=37$ ). Fifteen healthy subjects without any fracture were selected as control group (group 3; 3 males, 12 females; mean age 69.7 \pm 8.4 range 60 to 86 years). All fractures were simple falls due to low energy trauma. Bone mineral density measurements were performed with Lunar dual energy X-ray absorptiometry. Kyn/Trp levels were measured by high performance liquid chromatography. Interleukin (IL)-6 and IL-1 beta levels were measured with solid-phase sandwich enzyme-linked immunosorbent assay.

Results: All bone mineral density values were in agreement for osteoporosis and there was no significant difference between the two groups. Higher $\mathrm{Kyn} / \mathrm{Trp}$ ratios were observed in groups 1 and 2 compared to group 3. This difference was more significant in group 1 ( $p=0.0001$ ) than that in group 2 $(p=0.048)$. Also, group 1 had significantly higher Kyn/Trp ratio than group $2(p=0.011)$. There were significantly higher IL- 6 and lower IL-1 beta levels both in groups 1 and 2 compared to group 3 ( $p=0.0001)$. There was no significant difference between group 1 and group 2 in terms of IL- 6 and ILbeta levels. There was positive correlation with $\mathrm{Kyn} / \mathrm{Trp}$ ratio $(\mathrm{r}=0.581, \mathrm{p}=0.004)$ in group 2 . Also, significant correlation was detected between IL- 6 and IL-1 beta levels in the same group $(r=0.665, p=0.036)$.
\end{abstract}

Conclusion: Both increased degradation of tryptophan and ratio of Kyn/Trp indicate the relationship of immune activation with bone healing.

Keywords: Bone regeneration; indoleamine 2,3-dioxygenase; kynurenine; osteoporosis; tryptophan.

Osteoporosis-related fractures in females and males are highly dependent on bone mineral density (BMD) which is the gold standard for the diagnosis of osteoporosis but does not directly reflect deterioration in bone microarchitecture. ${ }^{1,2}$ The complex pathogenesis of osteoporosis is determined by the interaction of genetic, metabolic, and multiple environmental factors. Besides, free radicals and reactive oxygen species may involve in bone metabolism in which oxidative stress promotes the apoptosis of osteoblasts and the survival of osteoclasts. ${ }^{3,4}$ Elderly subjects are at high risk for bone fragility fractures because of senile alterations of $\mathrm{BMD}$, falls, life-style, rate of bone remodeling, changes in the geometry of bone macro- and microstructure, and also changes in nutritional status. ${ }^{5}$ Protein deficiency may contribute to the occurrence of hip fractures

Received: September 23, 2016 Accepted: December 08, 2016 Published online: March 24, 2017

Correspondence: Aylin Sepici Dinçel, MD. PhD. Gazi Üniversitesi Tıp Fakültesi Tıbbi Biyokimya Anabilim Dalı, 06500 Beşevler, Ankara, Turkey.

Tel: +90 312 - 2026949 e-mail: asepicidincel@gmail.com

○2017 Turkish League Against Rheumatism. All rights reserved. 
associated with lower BMD at the proximal femur by reducing muscle strength and impairing movement coordination. ${ }^{6,7}$

Indolamine 2,3-dioxygenase (IDO), first and rate-limiting enzyme of kynurenine (Kyn) pathway, is a tryptophan (Trp) degrading enzyme having immunoinflammatory effects. The cellular immune activation can be either monitored by Trp degradation or kynurenine and tryptophan (Kyn/Trp) ratio. ${ }^{8}$ High serum levels of proinflammatory cytokines, cytokine-soluble receptors, and $\mathrm{C}$-reactive protein have been associated with increased risk of fractures. ${ }^{9-12}$ The immune system influences differentiation and activity of bone cells within the bone microenvironment. ${ }^{13,14}$ Thus, in this study, we aimed to evaluate Trp degradation and clarify whether altered levels of Kyn/Trp ratio could be correlated to osteoporotic hip fractures via immune system.

\section{PATIENTS AND METHODS}

This prospective cohort study was conducted at Department of Orthopedics and Traumatology, Ankara Training and Research Hospital, September 2006 and September 2008 that included 60 patients with osteoporotic hip fracture (20 males, 40 females, mean age $76.6 \pm 6.9$ years; range 59 to 95 years). Patients were divided into two as patients with collum femoris fractures (group $1 ; n=23$ ) and intertrochanteric fractures (group 2; $n=37$ ). Fifteen healthy subjects without any fracture and having the same inclusion criteria were selected as control group (group 3; 3 males, 12 females; mean age $69.7 \pm 8.4$; range 60 to 86 years). All fractures were simple falls due to low energy trauma. None of the patients or controls had neoplastic pathology of bone, long-term corticosteroid usage, bone metabolism disease or arthritis or any other metabolic disease. BMD measurements were performed with Lunar dual energy X-ray absorptiometry. The measurements were performed on the intact side of the hip at fracture groups. BMD measurements were obtained as femoral neck, wards, trochanteric, and total BMD values. The study protocol was approved by the Ankara Training and Research Hospital Ethics Committee (0186/26.04.2006) and a written informed consent was obtained from all subjects before surgical procedures. The study was conducted in accordance with the principles of the Declaration of Helsinki.

Peripheral venous blood samples were taken after the fasting state of all subjects admitted to the hospital within the first 24 hours before the surgery. They were centrifuged at $3000 \times \mathrm{g}$ for 10 minutes for serum separation. All samples were stored at $-80{ }^{\circ} \mathrm{C}$ until Trp and Kyn analyses. L-tryptophan (Sigma Aldrich Corp., MA, USA), L-kynurenine (Sigma Aldrich Corp., MA, USA), gradient grade acetonitrile (Sigma Aldrich Corp., MA, USA), trichloroacetic acid (Merck), glacial acetic acid (Merck), sodium acetate (Merck), Supelco LC18 DB (15 $\mathrm{cm} \times 4 \mathrm{~mm}$ ID., $3 \mu \mathrm{m})$ analytical column and Supelguard LC18 DB $(2 \mathrm{~cm})$ guard column (Supelco), Hewlett-Packard Model 1050 high performance liquid chromatography HPLC pump were used in this study.

Serum Trp and Kyn levels were measured by high performance liquid chromatography with ultraviolet detection. Briefly, $100 \mu \mathrm{L}$ of the serum sample was mixed with $13 \mu \mathrm{L}$ $40 \%$ perchloric acid for protein precipitation, followed by vortex-mixing for one minute and centrifuged at $15000 \times \mathrm{g}$ for 10 minutes at $4{ }^{\circ} \mathrm{C}$. Of the supernate, $10 \mu \mathrm{L}$ was injected into the high performance liquid chromatography system (Thermo Finnigan Surveyor) for analysis. The chromatographic separation was carried out using the mobile phase consisting of $15 \mathrm{mmol} / \mathrm{L}$ acetate buffer $(\mathrm{pH}: 4.0)$ and acetonitrile $(98: 2, \mathrm{v} / \mathrm{v})$ at a flow rate of $0.8 \mathrm{~mL} /$ minute. A Supelcosil ${ }^{\mathrm{TM}}$ LC-18-DB (Sigma-Aldrich, St. Louis, MO, USA) analytical column (150 mm $\times 4 \mathrm{~mm}$ ID., $3 \mu \mathrm{m})$ was used for the analysis. The eluate was monitored by the programmed wavelength detection setting at $360 \mathrm{~nm}$ for Kyn and at $278 \mathrm{~nm}$ for Trp. The ratio of Kyn/Trp concentrations was calculated to estimate the activity of indolamine 2,3-dioxygenase. ${ }^{15}$

Human interleukin (IL)-6 levels were determined by using a solid-phase sandwich enzyme-linked immunosorbent assay BioSource Immunoassay Kit (BioSource International, Inc., Camarillo, CA, USA; Cat No: KHCOO61). Human IL-1 beta was also determined by using the same method (BioSource Immunoassay Kit; BioSource International, Inc., Cat No: KHCOOII). 


\begin{tabular}{|c|c|c|c|}
\hline & Group 1 & Group 2 & Group 3 \\
\hline & Mean \pm SD & Mean \pm SD & Mean \pm SD \\
\hline Kynurenine $(\mu \mathrm{mol} / \mathrm{L})$ & $2.7 \pm 0.8$ & $2.3 \pm 0.8$ & $2.6 \pm 0.7$ \\
\hline Tryptophan $(\mu \mathrm{mol} / \mathrm{L})$ & $25.0 \pm 8.8 \dagger$ & $30.8 \pm 11.9^{* *}$ & $41.5 \pm 9.2$ \\
\hline Kynurenine/tryptophan $\left(\mathrm{x} 10^{3}\right)$ & $118.2 \pm 50.8 \dagger, \neq$ & $83.6 \pm 34.8^{*}$ & $63.0 \pm 18.1$ \\
\hline Interleukin 6 (pg/mL) & $51.3 \pm 33.8 \dagger$ & $73.3 \pm 46.3 \dagger$ & $11.7 \pm 5.4$ \\
\hline Interleukin $1-\beta(\mathrm{pg} / \mathrm{mL})$ & $4.0 \pm 0.6 \dagger$ & $4.2 \pm 0.7 \dagger$ & $4.6 \pm 0.1$ \\
\hline
\end{tabular}

\section{Statistical analysis}

All results were presented as mean \pm standard deviation as well as median and interquartile ranges. Distribution characteristics of the variables were tested using the Kolmogorov Smirnov test. Statistical comparison between groups was performed with Mann-Whitney U test. The correlations between the independent parameters were assessed by Spearman's rank correlation analysis. A $p$ value of $<0.05$ was considered statistically significant. SPSS version 11.5 software (SPSS Inc., Chicago, IL, USA) was used for statistical analysis.

\section{RESULTS}

Neck, trochanter, wards, and total BMD values were compatible with osteoporosis and no significant differences were observed between the two groups of patients in terms of all BMD values. The related data was published in our previous study. ${ }^{16}$

Mean values of measured parameters were given in Table 1 . The median interquartile ranges of Kyn $(\mu \mathrm{mol} / \mathrm{L}), \operatorname{Trp}(\mu \mathrm{mol} / \mathrm{L})$ and Kyn/Trp in the study groups were 2.57 (2.05-3.19), 21.30 (18.53-33.53), 114.81 (74.72-151.96), respectively for group 1; 2.10 (1.76-2.87), 30.12 (21.05-35.24), 80.74 (56.34-98.57) for group 2; and 2.37 (1.833.23), 42.37 (35.56-46.31), 59.85 (48.50-75.50) for group 3. There was no statistically significant difference among groups in terms of Kyn levels (Figure 1a). There were significantly decreased Trp levels both in group $1(p=0.0001)$ and group 2 $(p=0.003)$ compared to group 3 (Figure $1 b)$. Higher Kyn/Trp ratios were observed in patient groups. Compared to group 3, this difference was more significant in group $1(p=0.0001)$ than that in group 2 ( $p=0.048)$. Also, group 1 had significantly higher Kyn/Trp value than group $2(p=0.011)$ (Figure 1c, Table 1).

The median interquartile ranges of IL- 6 $(\mathrm{pg} / \mathrm{mL})$ and IL-1 beta levels $(\mathrm{pg} / \mathrm{mL})$ were 30.91 (24.66-81.08), 4.14 (4.12-4.16), respectively for group 1 (eligible data $n=18$ ); 82.20 (19.18-109.23), 4.18 (4.12-4.19) for group 2 (eligible data $\mathrm{n}=24)$; and 10.86 (8.22-14.50), 4.54 (4.52-4.60) for group 3. There was no significant difference between group 1 and group 2 in terms of IL- 6 and IL-1 beta levels. However, there were significantly higher IL-6 and lower IL-1 beta levels both in group 1 and group 2 compared to group 3 (Table 1 ).

In group 2, serum IL-6 levels negatively correlated with Trp levels $(r=-0.444, p=0.034)$ and positively correlated with Kyn/Trp levels $(r=0.581, p=0.004)$ (Figure 2). Also, there was a significant correlation between IL- 6 and IL-1 beta levels in group $2(\mathrm{r}=0.665, \mathrm{p}=0.036)$. There was no significant correlation between Kyn/Trp and IL-6 in group 1 ( $r=-0.138$, $\mathrm{p}=0.610)$ and group $3(\mathrm{r}=0.061, \mathrm{p}=0.830)$. Only Trp levels correlated to IL-1 beta levels in group $3(\mathrm{r}=0.552, \mathrm{p}=0.046)$. In addition, Kyn/Trp positively correlated with age only in group 2 ( $\mathrm{r}=0.378, \mathrm{p}=0.027)$.

\section{DISCUSSION}

The main findings of our study are increased Kyn/Trp ratio in patients with hip fracture with respect to healthy subjects and in patients with intertrochanteric fracture when compared to those with collum femoris fracture. Since the population of our world is aging, the burden of fragility fractures is a constantly increasing problem. 
(a)

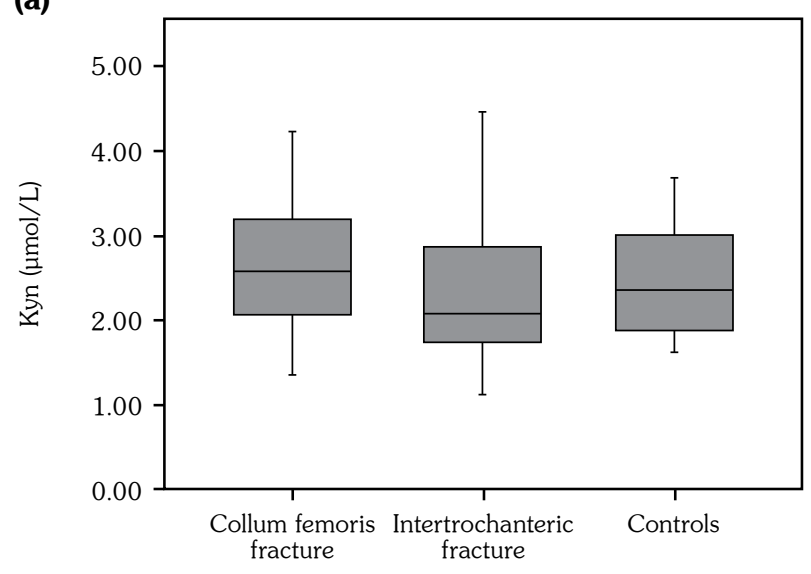

(b)

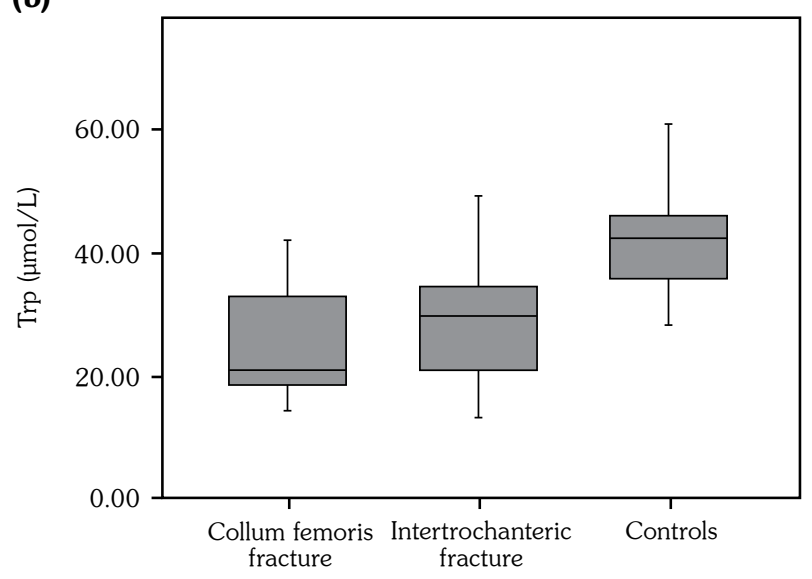

(c)

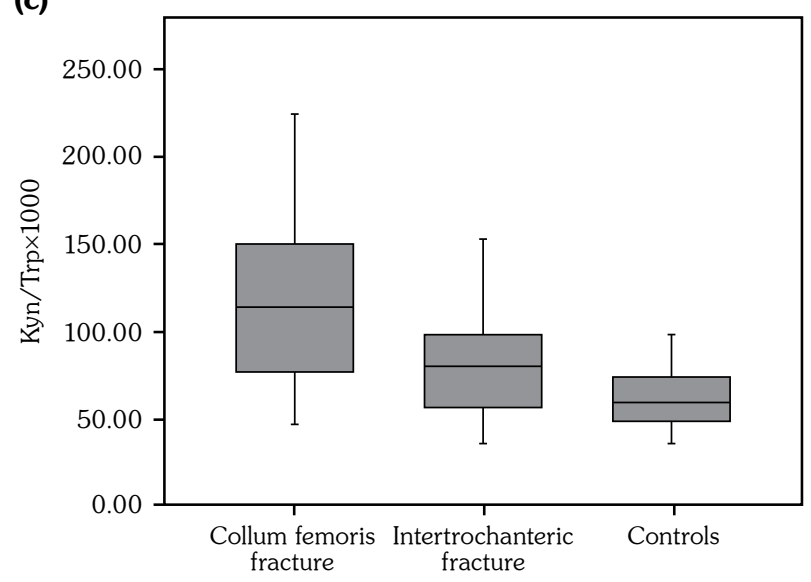

Figure 1. (a) Box plots of kynurenine, (b) tryptophan and (c) kynurenine/tryptophan ratio for collum femoris fracture, intertrochanteric fracture, and healthy control groups. Kyn: Kynurenine; Trp: Tryptophan; Kyn/Trp: Kynurenine to tryptophan.
There are many biochemical and physiological changes associated with aging.

In our previous studies, we discussed the risk assessments for hip fractures by proximal femur geometric measurements and genetics. ${ }^{1,17}$ Besides in a recent study, we evaluated the bone morphogenetic proteins, mostly focusing on the usefulness of biochemical markers for risk assessment. ${ }^{16}$ Here, our goal was to better understand IDO's role in bone metabolism via two different anatomical types of hip fracture groups compared to healthy control group. Our results indicate that IDO, a known modulator of immune response pathways, can play distinctively depending on the type of fracture which is related with the patient's general body resistance. Patients with intertrochanteric fracture have higher mortality than patients with femoral neck fracture not depending on the actual side of injury but depending on being older and sicker on admission. ${ }^{18,19}$ However, our results showed a significant correlation between Kyn/Trp and age in only patients with intertrochanteric fracture. Vidal et al. ${ }^{19}$ presented their study results first in American Society for Bone and Mineral Research 2010 Annual Meeting and emphasized the anabolic effect of interferon gamma to upregulate a set of genes associated with a Trp degradation pathway, in osteogenic differentiating human mesenchymal stem cells and very potent

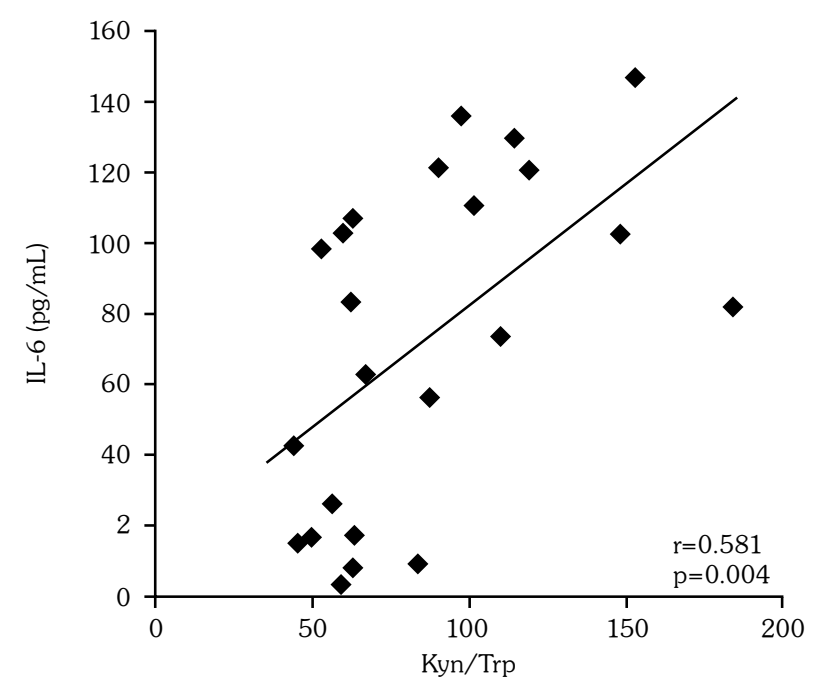

Figure 2. Association between kynurenine to tryptophan ratio and serum interleukin- 6 concentration in patients with intertrochanteric fracture (Spearman's rank correlation=0.581, $\mathrm{p}=0.004$ ). IL-6: Interleukin-6; Kyn/Trp: Kynurenine to Tryptophan. 
stimulatory effect of interferon gamma on IDO activity. They identified Trp degradation through the Kyn pathway that is exclusively activated in MSC during osteogenic conditions. In accordance with this study, the increased ratio of Kyn to Trp in patients with collum femoris fracture might indicate an osteoblastogenesis with better progress of fracture. An explanation for the higher IDO activity might be activated cellular immunity, which may be the result of an increased level of interferon gamma. Ozkan et al. ${ }^{20,21}$ suggested in their previous studies that the altered ratios of Kyn/Trp at cardiovascular disease and rheumatoid arthritis patients were associated with immune and inflammatory states.

Indolamine 2,3-dioxygenase has emerged as a pivotal modulator/regulator of the immune response. ${ }^{22}$ IDO helps in activation of T-regulatory cells, resulting in containment of hyperinflammatory responses and inhibition of T-helper 17 cells recruitment. ${ }^{23}$ In previous studies, IDO was shown to be a vital enzyme used by cells to modulate the host immune response..$^{24,25}$ Also, fracture healing has been divided into three distinct phases as inflammation, regeneration, and remodeling. In accordance with this knowledge, one may suggest imposed/ affected osteoblast/osteoclast, osteoblastogenesis, which can depend on the expression of IDO to induce its antiinflammatory effects via bone resorption and formation. ${ }^{26}$ The increased ratio of Kyn/Trp in both fracture patients, which was higher in collum femoris patients than in intertrochanteric fracture patients, may be related with host immune response.

In present study, the Trp concentrations of patient groups were lower than control group, which is compatible with the novel knowledge. As mentioned in different studies, ${ }^{27-29}$ the degradation of Trp could be formed around the inflamed surface and it is speculated that the altered expression of IDO might cause the inhibition of inflammatory cascades and prevent or slow down the tissue damage. Although immune function of osteoclasts is not known exactly, their activity can be regulated by activated $T$ cells and their cytokines. Also, in our study, Kyn/Trp ratio was correlated with IL-6 levels in patients with intertrochanteric fractures.
In conclusion, the representativeness of the Kyn/Trp ratio in relation with immune reaction and expression of pro-inflammatory cytokines is still hypothetical; the increased degradation of Trp and the Kyn/Trp ratio may indicate immune activation and increased macrophage IDO activity of a low energy trauma induced osteoporotic hip fracture. These may be the cause or consequence of hip fracture and assist in developing novel therapeutic strategies for human diseases involving both the bone and immune system pathologies.

\section{Declaration of conflicting interests}

The authors declared no conflicts of interest with respect to the authorship and/or publication of this article.

\section{Funding}

The authors received no financial support for the research and/or authorship of this article.

\section{REFERENCES}

1. Dinçel VE, Sengelen M, Sepici V, Cavuşoğlu T, Sepici $\mathrm{B}$. The association of proximal femur geometry with hip fracture risk. Clin Anat 2008;21:575-80.

2. Lorentzon M, Landin K, Mellström D, Ohlsson C. Leptin is a negative independent predictor of areal BMD and cortical bone size in young adult Swedish men. J Bone Miner Res 2006;21:1871-8.

3. Chen RM, Chen TL, Chiu WT, Chang CC. Molecular mechanism of nitric oxide-induced osteoblast apoptosis. J Orthop Res 2005;23:462-8.

4. Forrest CM, Mackay GM, Oxford L, Stoy N, Stone TW, Darlington LG. Kynurenine pathway metabolism in patients with osteoporosis after 2 years of drug treatment. Clin Exp Pharmacol Physiol 2006;33:1078-87.

5. Bonjour JP, Schurch MA, Rizzoli R. Nutritional aspects of hip fractures. Bone 1996;18:139-144.

6. Geinoz G, Rapin CH, Rizzoli R, Kraemer R, Buchs B, Slosman $\mathrm{D}$, et al. Relationship between bone mineral density and dietary intakes in the elderly. Osteoporos Int 1993;35:242-8.

7. Heaney RP. Nutritional factors in osteoporosis. Annu Rev Nutr 1993;13:287-316.

8. Munn DH, Mellor AL. Indoleamine 2,3 dioxygenase and metabolic control of immune responses. Trends Immunol 2013;34:137-43.

9. Barbour KE, Boudreau R, Danielson ME, Youk $\mathrm{AO}$, Wactawski-Wende $\mathrm{J}$, Greep $\mathrm{NC}$, et al. Inflammatory markers and the risk of hip fracture: the Women's Health Initiative. $\mathrm{J}$ Bone Miner Res 2012;27:1167-76. 
10. Ishii S, Cauley JA, Greendale GA, Crandall CJ, Danielson ME, Ouchi Y, et al. C-reactive protein, bone strength, and nine-year fracture risk: data from the Study of Women's Health Across the Nation (SWAN). J Bone Miner Res 2013;28:1688-98.

11. Nakamura K, Saito T, Kobayashi R, Oshiki R, Oyama $\mathrm{M}$, Nishiwaki $\mathrm{T}$, et al. C-reactive protein predicts incident fracture in community-dwelling elderly Japanese women: the Muramatsu study. Osteoporos Int 2011;22:2145-50.

12. Schett G, Kiechl S, Weger S, Pederiva A, Mayr A, Petrangeli $\mathrm{M}$, et al. High-sensitivity $\mathrm{C}$-reactive protein and risk of nontraumatic fractures in the Bruneck study. Arch Intern Med 2006;166:2495-501.

13. Apalset EM, Gjesdal CG, Ueland PM, Øyen J, Meyer $\mathrm{K}$, Midttun $\varnothing$, et al. Interferon gamma (IFN- $\gamma$ )mediated inflammation and the kynurenine pathway in relation to risk of hip fractures: the Hordaland Health Study. Osteoporos Int 2014;25:2067-75.

14. Lorenzo J, Horowitz M, Choi Y. Osteoimmunology: interactions of the bone and immune system. Endocr Rev 2008;29:403-40.

15. Zhang X, He Y, Ding M. Simultaneous determination of tryptophan and kynurenine in plasma samples of children patients with Kawasaki disease by highperformance liquid chromatography with programmed wavelength ultraviolet detection. J Chromatogr B Analyt Technol Biomed Life Sci 2009;877:1678-82.

16. Dincel VE, Sepici-Dincel A. The importance and the differences of bone morphogenetic proteins for osteoporotic hip fractures. Acta Orthop Belg 2014;80:216-21.

17. Dinçel E, Sepici-Dinçel A, Sepici V, Ozsoy H, Sepici B. Hip fracture risk and different gene polymorphisms in the Turkish population. Clinics (Sao Paulo) 2008;63:645-50.

18. Fox KM, Magaziner J, Hebel JR, Kenzora JE, Kashner TM. Intertrochanteric versus femoral neck hip fractures: differential characteristics, treatment, and sequelae. J Gerontol A Biol Sci Med Sci 1999;54:635-40.

19. Vidal C, Li W, Santner-Nanan B, Lim CK, Guillemin GJ, Ball HJ, et al. The kynurenine pathway of tryptophan degradation is activated during osteoblastogenesis. Stem Cells 2015;33:111-21.

20. Ozkan Y, Sukuroglu MK, Tulmac M, Kisa U, Simsek B. Relation of kynurenine/tryptophan with immune and inflammatory markers in coronary artery disease. Clin Lab 2014;60:391-6.

21. Ozkan Y, Mete G, Sepici-Dincel A, Sepici V, Simsek B. Tryptophan degradation and neopterin levels in treated rheumatoid arthritis patients. Clin Rheumatol 2012;31:29-34.

22. Baban B, Chandler PR, Sharma MD, Pihkala J, Koni PA, Munn DH, et al. IDO activates regulatory T cells and blocks their conversion into Th17-like T cells. $\mathrm{J}$ Immunol 2009;183:2475-83.

23. Casado FL, Singh KP, Gasiewicz TA. Aryl hydrocarbon receptor activation in hematopoietic stem/progenitor cells alters cell function and pathway-specific gene modulation reflecting changes in cellular trafficking and migration. Mol Pharmacol 2011;80:673-82.

24. Ploder M, Spittler A, Schroecksnadel K, Neurauter G, Pelinka LE, Roth E, et al. Tryptophan degradation in multiple trauma patients: survivors compared with non-survivors. Clin Sci (Lond) 2009;116:593-8.

25. Brown RR, Ozaki Y, Datta SP, Borden EC, Sondel $\mathrm{PM}$, Malone DG. Implications of interferoninduced tryptophan catabolism in cancer, autoimmune diseases and AIDS. Adv Exp Med Biol 1991;294:425-35.

26. Stoffel K, Engler H, Kuster M, Riesen W. Changes in biochemical markers after lower limb fractures. Clin Chem 2007;53:131-4.

27. Fatokun AA, Hunt $\mathrm{NH}$, Ball HJ. Indoleamine 2,3-dioxygenase 2 (IDO2) and the kynurenine pathway: characteristics and potential roles in health and disease. Amino Acids 2013;45:1319-29.

28. Bozec A, Zaiss MM, Kagwiria R, Voll R, Rauh M, Chen Z, et al. T cell costimulation molecules CD80/86 inhibit osteoclast differentiation by inducing the IDO/ tryptophan pathway. Sci Transl Med 2014;235:235.

29. Li H, Lu Y, Qian J, Zheng Y, Zhang M, Bi E, et al. Human osteoclasts are inducible immunosuppressive cells in response to $\mathrm{T}$ cell-derived IFN- $\gamma$ and CD40 ligand in vitro. J Bone Miner Res 2014;29:2666-75. 